\title{
Primary Lymphoepithelioma-Like Carcinoma of the Lung: A Case Report
}

\author{
Serdar Özkan, Ülkü Yazıcı², Ertan Aydın, Esra Özaydın², Nurettin Karaoğlanoğlu ${ }^{1}$ \\ ${ }^{1}$ Department of Thoracic Surgery, Atatürk Training and Research Hospital for Chest Disease and Thoracic Surgery, Ankara, Turkey \\ ${ }^{2}$ Laboratory of Pathology, Atatürk Training and Research Hospital for Chest Disease and Thoracic Surgery, Ankara, Turkey
}

\begin{abstract}
Primary lymphoepithelioma-like carcinoma (LELC) is a rare form of lung cancer. It often originates in the nasopharynx, stomach, salivary gland and thymus. Most of the time, its localisation in this area is associated with Epstein-Barr Virus (EBV). Transthoracic needle biopsy findings, which were performed for a 68-year-old male patient with the complaints of cough and frequently recurring oral aphthae, and mass appearance on his chest radiography, were found to be consistent with non-small cell lung cancer. Nasopharyngeal biopsy carried out for frequently recurring aphthous lesions revealed EBV. The patient was exposed to right upper lobectomy and mediastinal dissection. Postoperative pathological findings were interpreted as evidence for LELC. We have presented our case with a literature review because lymphoepithelioma-like carcinoma is a rarely seen subtype of lung cancer.
\end{abstract}

Keywords: Epstein-Barr virus, lymphoepithelioma-like carcinoma, lung

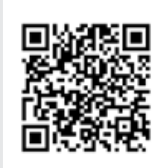

Received Date: 22.05 .2011

Accepted Date: 18.02.2012

Address for correspondence

Serdar Özkan, Department of Thoracic Surgery, Atatürk Training and Research Hospital for Chest Disease and Thoracic Surgery, Ankara, Turkey

E-mail: drozkan78@yahoo.com

(C) Copyright 2014 Turkish Respiratory Society (TRS) Eurasian J Pulmonol 2014

DOI: 10.5152/ejp.2014.76598

-Available online at www.eurasianjpulmonol.com

\section{INTRODUCTION}

Lymphoepithelioma-like carcinoma (LELC) mostly arises from the nasopharynx, stomach, salivary gland and thymus, and its localisation in this area is often associated with Epstein-Barr Virus (EBV). Primary LELC of the lung is quite rare and is differentiated as a histological entity from large cell undifferentiated carcinoma of the lung (1). Its association with EBV is variable and it includes significant geographical and ethnic variations. No association with EBV has been demonstrated in cases of LELC originating in the skin, cervix, oral cavity and other rare regions.

\section{CASE REPORT}

A 68-year-old male patient who had been followed up for the complaints of cough and yellow-green sputum production lasting for about 2.5 years was referred to our clinic due to the detection of a lung-localised tumour. The patient had a history of frequently recurring oral aphthae resistant to treatment and he had been operated upon due to benign prostatic hypertrophy 6 years ago. Moreover, in his family history, one of his siblings had died of lung cancer. In the physical examination of the patient who had been smoking one pack of cigarettes a day for 40 years, no pathology was found except oral aphthae. On the posteroanterior chest radiography and right lateral graphy of the patient, right upper zone-localised homogeneous density was observed. His computed tomography (CT) of the chest revealed an irregular-bordered mass lesion with a diameter of $3.5 \mathrm{~cm}$ with spicular extensions (Figure 1). On positron emission tomography PET/CT, SUVmax (maximum standardised uptake value) was found to be 8.62 for metabolic activity involvement of the mass in the posterior segment of the right upper lobe (Figure 2). No pathological metabolic activity involvement was detected other than identified mass. Screening for distant metastasis revealed no other mass lesion in cranial and abdominal organs. In pathological analysis of material obtained by transthoracic tru-cut biopsy, the mass was evaluated as non-small cell lung cancer. The Department of Otorhinolaryngology was consulted for the frequently recurring oral aphthous ulcer and medical treatment was initiated in the patient. Nasopharyngeal biopsy was performed since the patient did not respond to the treatment, and EBV was identified upon examination of the biopsy material. The result of concurrent EBV EBNA IgG was found to be $4.95 \mathrm{U} / \mathrm{mL}(+)$ and resection was decided upon for the patient. Right upper lobectomy, 


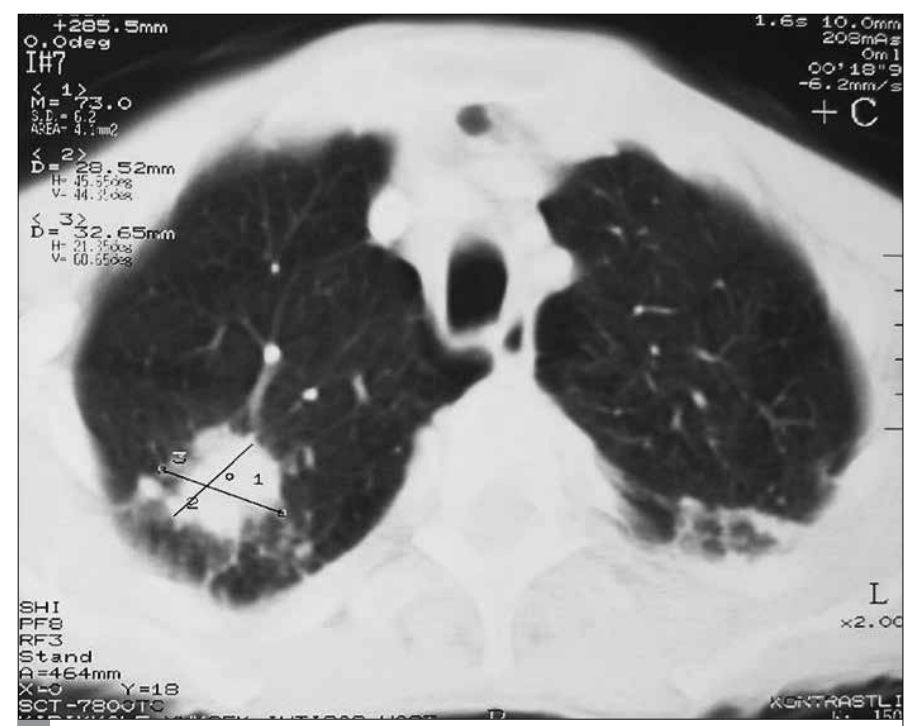

Figure 1. Thoracic CT imaging of the mass lesion

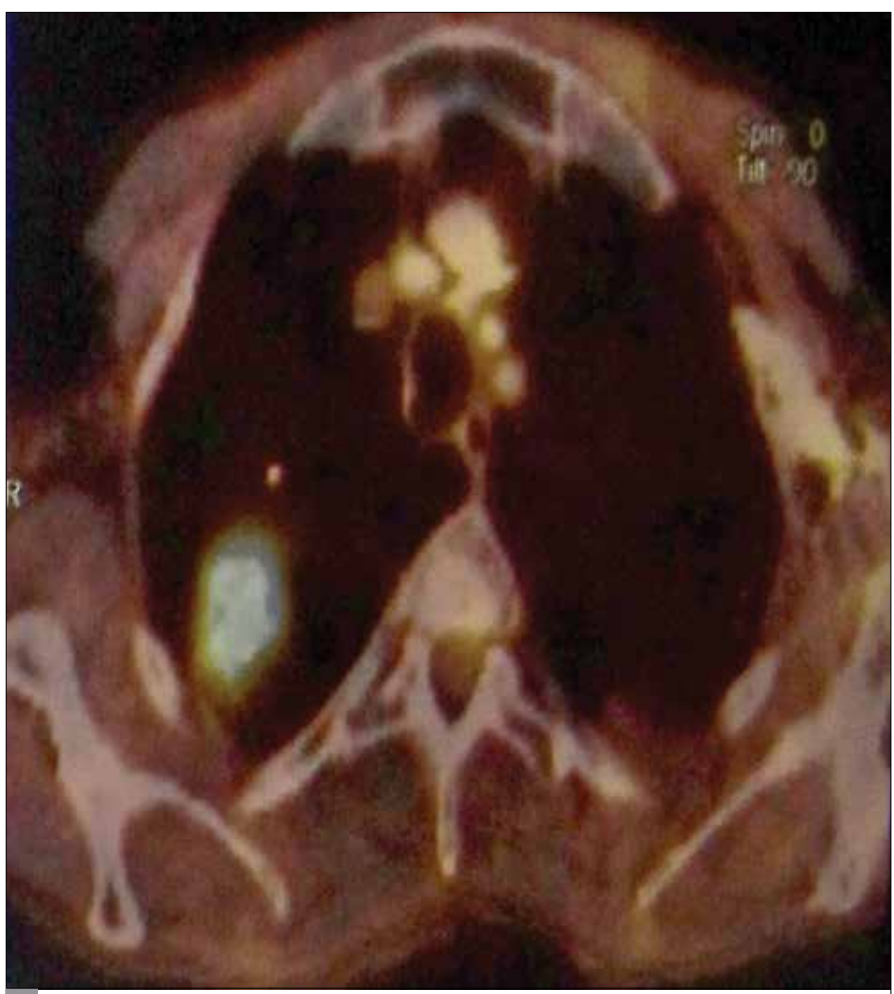

Figure 2. PET/CT imaging of the mass lesion

right posterolateral thoracotomy and lymph node dissection (lymph nodes numbered 4-7-10-11) were performed. Upon conclusion of histopathological examination, the pathology report was LELC reactive lymph nodes (lymph nodes numbered 4-7-10-11), and negative surgical tumour margins (figure 3 ). The patient had no postoperative complication and was discharged with the advice of chemotherapy. The patient refused chemotherapy and he has been under our foolow-upfor 44 months without any problems.

\section{DISCUSSION}

Lymphoepithelioma-like carcinoma (LELC) of the lung is a rarely seen tumour and its frequency has been reported to range from $0.87 \%$

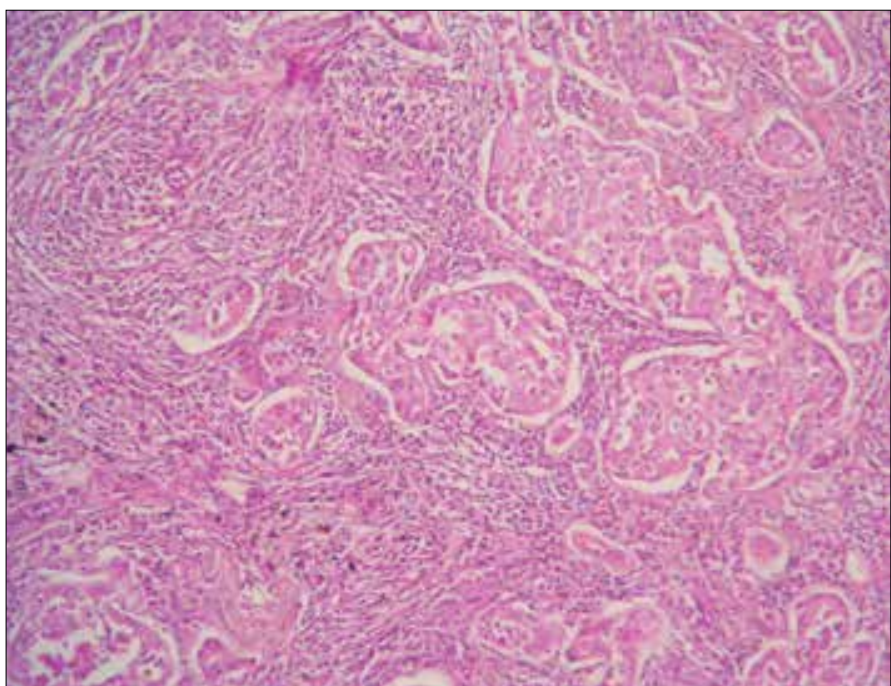

Figure 3. Histopathological view (H.E. x 40)

to $3.6 \%$ among other lung malignancies (2). It mostly affects Asians, especially the Chinese population, in comparison to Caucasians (1). As in our case, this tumour is commonly seen in adults (3). No gender tendency has been found to be associated with LELC.

LELC appears in organs such as the nasopharynx, stomach, lung, salivary gland and thymus, all of which originate from the foregut. In the localisations of these regions, LELC was reported to be associated with EBV infection (4-6). However, no association with EBV infection has been found for the skin, vagina, cervix, and bladder involvements, which are seen less frequently $(7,8)$. The relationship between LELC and smoking was demonstrated in $25-40 \%$ of cases, whereas this rate was $90 \%$ and above for other forms of lung cancer (9). Our case also had a history of smoking.

According to the immunohistochemical and molecular findings obtained from some microbiological studies, EBV-induced hyperplasia and premalignant lesions result from epithelial proliferation occurring due to the interaction between the virus and CD21 receptor on the surface of B lymphocytes (10).

Lymphoepithelioma-like carcinoma was first described by Begin and colleagues in 1987 (11). It was differentiated from large cell undifferentiated carcinoma of the lung as a histological entity (12). The disease can be incidentally detected with the appearance of a solitary pulmonary nodule or it can be noticed in the generalised severe stage.

During the pathological evaluation of our case, it was found that the tumour consisted of cells with a large vesicular nucleus and with prominent eosinophilic nucleus, characterised by a syncytial growth pattern, and sometimes intense lymphocytic infiltrations. This distinct lymphocytic reaction arises from polymorphonuclear leukocytes, mature lymphocytes, and plasmocytes (Figure 2). On histopathological examination of the tumour, mixed-type inflammatory cell infiltration was observed. Absence of monoclonality in lymphoid cells is important for differentiating the tumour from lymphoid malignancies. Considering lung tumours with highly heterogeneous structures, it is impossible to diagnose the rarely seen LELC through small biopsy samples that represent only a small part of the tumour. 
In those cases diagnosed as primary LELC of the lung, if there is no suspected lesion in the nasopharyngeal region and the lesion cannot be visualised on $\mathrm{CT}$, it is not recommended to conduct a biopsy on this region (1). In their study, Bildirici et al. (9) reported that the nasopharyngeal region was clean in the patient diagnosed with primary LELC in the stage of T2NOMO and negative in terms of EBV.

A high incidence of systemic metastases can be seen in cases with LELC of the lung. These metastases are prominently more chemosensitive compared to other non-small cell lung malignancies (1). Long-term follow-up data about rarely seen LELC of the lung are quite limited and further studies are required on this issue. There are some studies suggesting that the best life expectancy is approximately 2 years (2). Han et al. (13) stated in their study that the prognosis of LELC cases was better than that of other lung cancer cases. In this study, the recurrence of tumour and the presence of $5 \%$ or greater necrosis in the tumour tissue, rather than metastasis, were found to be associated with poor prognosis.

Nasopharyngeal LELC is a highly radiosensitive tumour and a number of current studies have suggested that it is also chemosensitive (2). However, for LELC of the lung, the success of radiotherapy and chemotherapy in treatment is unclear. Chemotherapy, radiotherapy or a combination of these two techniques can be used for inoperable cases. Adjuvant radiotherapy and chemotherapy provide advantages for operable patients (1).

\section{CONCLUSION}

If the cases of LELC are clinically operable, then surgical resection procedures should be performed.

Informed Consent: Written informed consent was obtained from patient who participated in this study.

Peer-review: Externally peer-reviewed.

Author Contributions: Concept - S.Ö., Ü.Y.; Design - S.Ö.; Supervision - Ü.Y., N.K.; Resource - S.Ö., E.A.; Analysis\&/or Interpretation - E.Ö.; Literature Search S.Ö., E.Ö.; Writing - S.Ö.; Critical Reviews - N.K.

Conflict of Interest: No conflict of interest was declared by the authors.
Financial Disclosure: The authors declared that this study has received no financial support.

\section{REFERENCES}

1. Anthony TCC, Peter MLT, Kwok CL, Wing YC, John HS, Chow MD, et al. Multimodality treatment of primary lymphoepithelioma like carcinoma of the lung. Cancer 1998; 83: 925-9.

2. Han AJ, Xiong M, Zong YS. Association of Epstein Barr virus with lymphoepithelioma like carcinoma of the lung in southern china. Am J Clin Pathol 2000; 114: 220-6.

3. John K.C.C, Pak-kwain H, William Y.W, et al. Primary lymphoepithelioma like carcinoma of the lung. Cancer 1995; 76: 413-22.

4. Chan JK, Hui PK, Tsang WY, Law CK, Ma CC, Yip TT, et al. Primary lymphoepithelioma-like carcinoma of the lung. A clinicopathologic study of 11 cases. Cancer 1995; 76: 413-22.

5. Lezzoni JC, Gaffey MJ, Weiss LM. The role of Epstein Barr virus in lymphoepithelioma like carcinomas. Am J Clin Pathol 1995; 103: 308-15.

6. Oda K, Tamaru J, Takenouchi T, Mikata A, Nunomura M, Saitoh N, et al. Association of Epstein Barr virus gasric carcinoma with Ihymphoid stroma. Am J Pathol 1993; 143: 1063-74.

7. Land AC, Breer WA, Wick MR. Lymphoepithelioma like carcinoma of the skin with apparent origin in the epidermis: A pattern or an entity? A case report. Cancer 1999; 85: 884-90.

8. Weiss LM1, Movahed LA, Butler AE, Swanson SA, Frierson HF Jr, Cooper $\mathrm{PH}$, et al. Analysis of lymphoepithelioma and lymphoepithelioma like carcinomas of different organs for Epstein Barr viral genomes by in situ hybridization. Am J Surg Pathol. 1989; 13: 625-31.

9. Bildirici K, Ak G, Peker B, Metintaş M, Alataş F, Erginel S, et al. Primary lymphoepithelioma-like carcinoma of the lung. Tüberküloz ve Toraks Derg 2005; 53: 69-73.

10. Grinstein S, Preciado MV, Gattuso P, Chabay PA, Warren WH, De Matteo E, et al. Demonstration of Epstein-Barr virus in carcinomas of various sites. Cancer Res 2002; 62: 4876-8.

11. Begin LR, Eskandari J, Joncas J, Panasci L. Epstein-Barr Virus related lymphoepithelioma-like carcinoma of lung. J Surg Oncol 1987; 36: 280-3.

12. Travis W.D, Brambilla E, Muller-Hermelink H.K, et al. World Health Organization Classification. Pathology and genetics of tumors of the lung, pleura, thymus and heart. IARC Press: Lyon 2004.

13. Lyon Han AJ1, Xiong M, Gu YY, Lin SX, Xiong M. Lymphoepithelioma-like carcinoma of the lung with a better prognosis. Am J Clin Pathol 2011; 115: 841-50. 